\title{
Detección inmunohistoquímica del antígeno del virus diarrea viral bovina en fetos y neonatos bovinos
}

\author{
Lertora, W.J.; Frías, M.L.; Sánchez Negrette, M. \\ Cátedra de Patología General y Sistemática, Facultad de Ciencias Veterinarias, \\ UNNE, Sargento Cabral 2139, Corrientes (3400), Argentina. \\ Tel/fax 03783-425753. E-mail: patgral@vet.unne.edu.ar.
}

\begin{abstract}
Resumen
Lertora, W.J.; Frías, M.L.; Sánchez Negrette, M.: Detección inmunohistoquímica del antígeno del virus diarrea viral bovina en fetos y neonatos bovinos. Rev. vet. 20: 1, 31-36, 2009. Los objetivos del trabajo fueron investigar la participación del virus diarrea viral bovina (vDVB) como causal de abortos y mortalidad neonatal en bovinos de la región del nordeste argentino y determinar la distribución antigénica del virus en diversos órganos fetales. Tejidos de 40 fetos y 11 neonatos bovinos fijados en formalina y embebidos en parafina fueron procesados mediante un método inmunohistoquímico. El antígeno vDVB fue detectado en tres fetos, no detectándose neonatos positivos. En todos los fetos positivos se observó una amplia distribución del antígeno, visualizada como pigmento marrón granular de diferentes diámetros en el citoplasma de células epiteliales, neuronas, células gliales, macrófagos, células endoteliales, endocrinas y células de músculo liso de la mayoría los órganos estudiados. Las neuronas, células epiteliales, macrófagos y células del músculo liso vascular fueron los tipos celulares que evidenciaron la mayor concentración antigénica. Por ello, se resalta la conveniencia del análisis de encéfalo, piel y nódulo linfoide para la detección inmunohistoquímica de vDVB en fetos bovinos de abortos espontáneos. El vDVB está presente en el ganado bovino de la región, es responsable de originar abortos y pese al bajo porcentaje de fetos positivos $(7,5 \%)$ no debe subestimarse su importancia como patógeno de la reproducción.
\end{abstract}

Palabras clave: bovino, feto, virus diarrea viral bovina, inmunohistoquímica.

\begin{abstract}
Lertora, W.J.; Frías, M.L.; Sánchez Negrette, M.: Immunohistochemical detection of bovine viral diarrhea virus antigen in bovine aborted fetuses and neonates. Rev. vet. 20: 1 , 31-36, 2009. The objectives of this study were to investigate the involvement of the bovine viral diarrhea virus (BVDv) as a cause of abortions and neonatal mortality in cattle from northeastern Argentina, and to determine the antigenic distribution of virus in various fetal organs. Tissues from 40 bovine fetuses and 11 neonates were fixed in formalin, embedded in paraffin and processed using an immunohistochemical method. The BVDv antigen was detected in three fetuses, whereas positive neonates were not detected. In all positive fetuses it was observed a wide distribution of the antigen, visualized as brown granular pigment of different diameters in the cytoplasm of epithelial cells, neurons, glial cells, macrophages, endothelial cells, endocrine and smooth muscle cells of most of the studied organs. Neurons, epithelial cells, macrophages and vascular smooth muscle cells were the cell types that showed the highest antigen concentration. These findings emphasize the convenience of the analysis of brain, skin and lymphoid nodule immunohistochemistry for the detection of BVDv in bovine fetuses from spontaneous abortions. The BVDv is present in bovine herds of the region, being responsible of abortions and, despite the low percentage of positive fetuses $(7.5 \%)$, its importance as a pathogen of the reproductive system should not be underestimated.
\end{abstract}

Key words: cattle, fetuses, bovine viral diarrhea virus, immunohistochemistry. 


\section{INTRODUCCIÓN}

El virus diarrea viral bovina (vDVB) es un importante patógeno del bovino, responsable de ocasionar una amplia variedad de manifestaciones clínicas y lesiones en diferentes órganos. Sin embargo, su mayor impacto es sobre la salud reproductiva del ganado originando ooforitis, muerte embrionaria, abortos, momificación, malformaciones congénitas, nacimiento de terneros débiles y de terneros persistentemente infectados ${ }^{8,16,21}$.

En la Argentina, las encuestas serológicas indican que la enfermedad tiene una amplia distribución y es endémica en la mayoría de las poblaciones bovinas ${ }^{15,18}$. Ha sido ampliamente demostrada la participación directa del vDVB como causal de abortos ${ }^{3,4,6}$ y enfermedad neonatal ${ }^{17}$ en el ganado de la Provincia de Buenos Aires. En el nordeste de Argentina, estudios serológicos recientes indican que la infección por vDVB es común ${ }^{13} \mathrm{y}$, sin embargo, existe carencia de información respecto a la situación del vDVB como causal de aborto y mortalidad neonatal ${ }^{7}$.

Por otra parte, no existen en el país estudios inmunohistoquímicos que determinen la localización antigénica del vDVB en fetos de abortos espontáneos. Esto indujo a montar un método inmunohistoquímico para investigar la posible participación del vDVB como causal de abortos y mortalidad neonatal en bovinos de nuestra región. En el mismo contexto, se estudió la localización y distribución antigénica del virus en diversos órganos fetales, reportándose las lesiones microscópicas.

\section{MATERIAL Y MÉTODOS}

Se analizaron 40 fetos y 11 neonatos bovinos remitidos al Laboratorio de Histopatología de nuestra Facultad. Los fetos procedían de las provincias de Santa Fe (Vera, Avellaneda, General Obligado) y Corrientes (Mercedes, El Sombrero, Empedrado, Riachuelo, Goya, Berón de Astrada y San Luis del Palmar). Los neonatos fueron enviados desde las provincias de Chaco (Quitilipi) y Corrientes (Capital, San Cosme, Ituzaingó, Riachuelo, Virasoro, Itá Ibaté y San Luis del Palmar).

Se tomaron muestras de diversos órganos $\mathrm{y}$ tejidos, los que fueron fijados en formol bufferado al $10 \%$ durante 24 horas, procesados según la técnica clásica para bloques parafinados, cortados a $5 \mu \mathrm{m}$ y montados en portaobjetos con polilisina. La detección antigénica del vDVB se realizó mediante la técnica inmunoenzimática biotina-streptavidina-peroxidasa.

Las secciones de tejidos fueron desparafinadas en xilol e hidratadas en concentraciones decrecientes de alcohol. La peroxidasa endógena se inactivó con una solución de peroxido de hidrógeno al 3\% en metanol durante 10 minutos. La recuperación antigénica se realizó con proteinasa $\mathrm{K}$ al $0,2 \%$ en cámara húmeda a $37^{\circ} \mathrm{C}$ durante 20 minutos. Como anticuerpo primario se utilizó el anticuerpo monoclonal 15.c.5 (Dr. E. Dubovi, Cornell University, Ithaca, NY) en dilución 1:6000. El anticuerpo primario se incubó con el tejido durante toda la noche en heladera entre $4^{\circ}$ y $6^{\circ} \mathrm{C}$. Para revelar la reacción antígeno anticuerpo se utilizó el sistema biotina-streptavidina-peroxidasa y el cromógeno diaminobenzidina ${ }^{14}$.

Como controles positivos y negativos se emplearon biopsias de piel de bovinos persistentemente infectados y sin infección, respectivamente, diagnosticados por el Dr. Germán Reinhardt del Instituto de Microbiología de la Facultad de Ciencias de la Universidad Austral de Chile. Para el estudio de las lesiones microscópicas todos los especimenes fueron coloreados con hematoxilina y eosina.

\section{RESULTADOS Y DISCUSIÓN}

El antígeno vDVB fue detectado en tres fetos, los restantes casos resultaron negativos. En los tres casos se observó idéntico patrón de tinción visualizado como pigmento marrón granular intracitoplasmático de diferentes diámetros. Este patrón de tinción es el esperado para una detección específica de partículas virales que se replican en el citoplasma. La localización del antígeno del vDVB en los tres fetos fue amplia y abarcó células epiteliales, neuronas, células gliales, macrófagos, células endoteliales, endocrinas y células de músculo liso (Tablas 1, 2 y 3). Las neuronas, macrófagos, células epiteliales y músculo liso vascular fueron los tipos celulares con mayor carga antigénica.

En piel, la inmunomarcación fue intensa en todas las células de la epidermis, folículos pilosos, glándulas, macrófagos y músculo liso (Figura 1). En el sistema nervioso central la inmunotinción presentó una amplia distribución localizada en distintos tipos de neuronas, células gliales, vasos sanguíneos, meninges y epéndimo del cerebro, cerebelo y tronco encefálico. Las neuronas de mayor tamaño y los vasos sanguíneos fueron las estructuras que evidenciaron la mayor intensidad de tinción en el tejido nervioso (Figura 2). En los nódulos linfoides los macrófagos presentaron intensa reacción, mientras que los linfocitos corticales resultaron negativos (Figura 3). Estas observaciones concuerdan con infecciones experimentales y naturales que demuestran en el feto una rápida y extensa replicación del vDVB en diferentes tipos celulares de diversos órganos, con especial tropismo por neuronas, células epiteliales y macrófagos 1,9, 10,12,20,22.

En cuanto a la distribución antigénica, se observaron dos patrones. Los fetos 1 y 2 presentaron una distribución antigénica difusa (inmunoreacción positiva en el $80 \%$ o más de la población celular) en tejido epitelial, nervioso, linfoide y endocrino. El feto 3 presentó una distribución antigénica multifocal (grupos de 2 a 5 células con inmunoreacción positiva) en tejido epitelial y difusa en tejido nervioso y linfoide. También se apreció diferencia en la intensidad de la inmunoreacción, siendo intensa a moderada en los fetos 1 y 2 , y moderada a leve en el feto 3. Estas diferencias podrían deberse a la carga antigénica que presentó cada feto, la cual es influenciada por numerosos factores tales como cepa y biotipo 
Tabla 1: Localización e intensidad de inmunotinción del antígeno vDVB en piel, sistema digestivo y pulmones de tres fetos bovinos de abortos espontáneos.

\begin{tabular}{|c|c|c|c|}
\hline Órganos & feto 1 & feto 2 & feto 3 \\
\hline \multicolumn{4}{|l|}{ Piel (oreja) } \\
\hline Epidermis & +++ & +++ & nd \\
\hline Células intersticiales de dermis (¿macrófagos?) & +++ & +++ & \\
\hline Folículos pilosos & +++ & +++ & \\
\hline Músculo liso piloerector & ++ & ++ & \\
\hline Glándulas sebáceas & +++ & +++ & \\
\hline Glándulas sudoríparas & +++ & ++ & \\
\hline Condrocitos & + & nd & \\
\hline \multicolumn{4}{|l|}{ Parótida } \\
\hline Epitelio de conductos secretores & ++ & ++ & nd \\
\hline Epitelio glandular & + & + & \\
\hline \multicolumn{4}{|l|}{ Lengua } \\
\hline Epitelio de la mucosa & nd & ++ & $+^{\mathrm{m}}$ \\
\hline Células intersticiales de submucosa (¿macrófagos?) & & +++ & - \\
\hline Neuronas de ganglios nerviosos & & +++ & - \\
\hline Glándulas salivares mucosas & & + & nd \\
\hline Glándulas salivares serosas & & ++ & nd \\
\hline Músculo estriado & & - & - \\
\hline \multicolumn{4}{|l|}{ Rumen, redecilla y omaso } \\
\hline Mucosa: $\quad$ Epitelio & ++ & nd & nd \\
\hline Músculo liso de muscular de la mucosa & ++ & & \\
\hline \multicolumn{4}{|l|}{ (redecilla y omaso) } \\
\hline Células intersticiales de lámina propia & +++ & & \\
\hline \multicolumn{4}{|l|}{ (¿macrófagos?) } \\
\hline Muscular: Músculo liso & ++ & & \\
\hline Neuronas del plexo mioentérico & +++ & & \\
\hline \multicolumn{4}{|l|}{ Abomaso } \\
\hline Mucosa: Células epiteliales de base glandular & ++ & nd & $+^{\mathrm{m}}$ \\
\hline Muscular: Músculo liso & ++ & & - \\
\hline Neuronas del plexo mioentérico & +++ & & $+\mathrm{m}$ \\
\hline Intestino delgado & & & \\
\hline Mucosa: Células epiteliales de criptas & nd & nd & $+^{\mathrm{m}}$ \\
\hline Muscular: Músculo liso & & & - \\
\hline Neuronas del plexo mioentérico & & & $+^{\mathrm{m}}$ \\
\hline Hígado & & & \\
\hline Células de Kupffer y endotelio sinusoidal & +++ & +++ & + \\
\hline Hepatocitos & + & +++ & - \\
\hline Epitelio de canales biliares & - & + & - \\
\hline Pulmones & & & \\
\hline Epitelio bronquiolos & nd & ++ & $+^{\mathrm{m}}$ \\
\hline Epitelio y endotelio de pared alveolar & & ++ & $+^{\mathrm{m}}$ \\
\hline Macrófagos alveolares & & - & +++ \\
\hline
\end{tabular}

nd: no disponible. m: multifocal. - : sin tinción. +: tinción débil. ++: tinción moderada. +++: tinción intensa (la evaluación de la intensidad de tinción se realizó en forma subjetiva utilizando al tejido control como patrón).

viral, estado inmune de la madre, edad gestacional y estado del desarrollo del sistema inmune fetal ${ }^{2,8,12,16}$.

Las lesiones microscópicas constatadas en el feto 1 fueron tumefacción axonal en cerebro, cerebelo, puente, tubérculos cuadrigéminos y obex. Dichos axones resultaron negativos a la inmunomarcación del antígeno; aunque sus cuerpos neuronales fueron fuertemente positivos. En el feto 3 se constató atrofia de tejido linfoide de timo y nódulos linfoides, atelectasia por aspiración del líquido amniótico en pulmones y necrosis de neu- ronas en estrato granular de corteza cerebelar y gliosis difusa de la sustancia blanca del cerebro y cerebelo. No se observaron lesiones microscópicas en el feto 2 .

Las lesiones histopatológicos reportadas en infecciones fetales naturales y experimentales son variables e inespecíficas. Se reportan distintas lesiones teratogénicas, especialmente del sistema nervioso central, desmielinización, procesos inflamatorios no purulentos, vasculitis, necrosis multifocal hepática, atrofia de 
Tabla 2: Localización e intensidad de inmunotinción del antígeno del vDVB en tejido nervioso de tres fetos bovinos de abortos espontáneos.

\begin{tabular}{|c|c|c|c|}
\hline Órganos & feto 1 & feto 2 & feto 3 \\
\hline \multicolumn{4}{|l|}{ Cerebro } \\
\hline Corteza: Neuronas capa molecular & + & + & $t^{\mathrm{a}}$ \\
\hline Neuronas capa granular & ++ & ++ & ++ \\
\hline Neuronas capa piramidal & +++ & +++ & ++ \\
\hline Células satélites & + & + & - \\
\hline Sustancia blanca: Células gliales & ++ & + & $+^{\mathrm{a}}$ \\
\hline Células germinales subependimo & ++ & nd & nd \\
\hline Células ependimarias & ++ & nd & nd \\
\hline \multicolumn{4}{|l|}{ Cerebelo } \\
\hline Corteza: Células germinales & ++ & + & + \\
\hline Neuronas capa molecular & + & + & $t^{\mathrm{a}}$ \\
\hline Neuronas capa granular & ++ & ++ & $+^{\mathrm{a}}$ \\
\hline Células de Purkinje & +++ & ++ & ++ \\
\hline Sustancia blanca: células Gliales & ++ & + & $+^{\mathrm{a}}$ \\
\hline \multicolumn{4}{|l|}{ Puente } \\
\hline Neuronas & +++ & ++ & ++ \\
\hline Células Gliales & + & + & $+^{\mathrm{a}}$ \\
\hline \multicolumn{4}{|l|}{ Tubérculos cuadrigéminos y Obex } \\
\hline Neuronas & +++ & nd & nd \\
\hline Células gliales & ++ & & \\
\hline Células germinales del periacueducto & ++ & & \\
\hline Células ependimarias & ++ & & \\
\hline \multicolumn{4}{|l|}{ Ganglio nervioso trigémino } \\
\hline Neuronas & +++ & nd & nd \\
\hline Células gliales & + & & \\
\hline \multicolumn{4}{|l|}{ Ganglio nervioso mesentérico } \\
\hline Neuronas & +++ & nd & nd \\
\hline
\end{tabular}

nd: no disponible. a: células aisladas. - : sin tinción. +: tinción débil. ++: tinción moderada. +++: tinción intensa (la evaluación de la intensidad de tinción se realizó en forma subjetiva utilizando al tejido control como patrón).

tejido linfoide y muchos casos no evidencian lesiones microscópicas ${ }^{1-3,20}$.

La principal característica de vDVB es su variabilidad genética y antigénica ${ }^{5,19}$. Por lo tanto, el empleo de un anticuerpo monoclonal en muestras fijadas en formalina puede originar resultados falsos negativos. Aunque no pudimos evaluar estos aspectos, creemos que la técnica empleada es una buena herramienta para el diagnóstico inmunohistoquímico del vDVB. El anticuerpo monoclonal 15.c.5 es una inmunoglobulina G2b que reacciona con un epitope de la glicoproteína viral Erns (glicoproteína E0) altamente conservada entre los pestivirus y resistente a los efectos de la fijación. Es capaz de detectar a biotipos citopáticos y no citopáticos, virus del genotipo 1 y 2 del vDVB, virus de la peste porcina clásica, virus de la enfermedad de la frontera del ovino y, posiblemente, pestivirus caprinos ${ }^{1,5,11}$ . Además, el empleo de este anticuerpo en la detección inmunohistoquímica del vDVB en tejidos de fetos fijados en formalina y embebidos en parafina, ha demostrado ser una técnica tan sensible como el aislamiento viral y en casos de fetos con avanzada autólisis la inmunohistoquímica se recomienda sobre el aislamiento viral, la inmunofluorescencia y la detección de antígeno por ELISA ${ }^{1,9,22}$.
En cuanto a la participación del vDVB como causal de abortos en nuestra región, y de acuerdo a nuestro estudio, la misma en principio resulta ser aparentemente baja, solamente encontramos 3 fetos positivos de 40

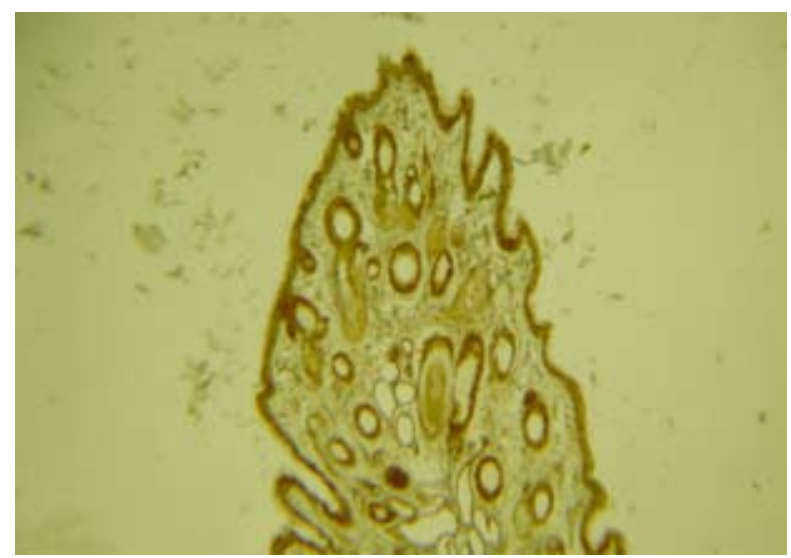

Figura 1: Piel de oreja, feto bovino $n^{\circ} 1$. Amplia distribución de la inmunotinción en células epiteliales de la epidermis y folículos pilosos, células de glándulas sebáceas y glándulas sudoríparas, células del músculo liso vascular y piloerector. Inmunotinción compatible con una infección persistente. Anticuerpo monoclonal 15.c.5, dilución 1:6000 (4x). 
Tabla 3: Localización e intensidad de inmunotinción del antígeno del vDVB en tejido linfoide, muscular y endocrino de tres fetos bovinos de abortos espontáneos.

\begin{tabular}{|c|c|c|c|}
\hline Órganos & feto 1 & feto 2 & feto 3 \\
\hline \multicolumn{4}{|l|}{ Nódulo linfoide } \\
\hline Macrófagos & +++ & nd & +++ \\
\hline Linfocitos corticales & - & & - \\
\hline \multicolumn{4}{|l|}{ Timo } \\
\hline Timocitos & nd & nd & - \\
\hline Células mononucleares del estroma (macrófagos?) & & & +++ \\
\hline \multicolumn{4}{|l|}{ Miocardio } \\
\hline Fibra muscular & $+^{\mathrm{a}}$ & $+^{\mathrm{a}}$ & - \\
\hline Células intersticiales & ++ & ++ & - \\
\hline Células mononucleares de coágulo sanguíneo & nd & +++ & nd \\
\hline \multicolumn{4}{|l|}{ Arterias (diferentes órganos) } \\
\hline Músculo liso & +++ & +++ & $+^{\mathrm{m}}$ \\
\hline Endotelio & + & + & - \\
\hline \multicolumn{4}{|l|}{ Músculo esquelético } \\
\hline Fibra muscular & - & nd & nd \\
\hline Células intersticiales (¿miosatélites?) & $++^{\mathrm{a}}$ & & \\
\hline Nervios & ++ & & \\
\hline \multicolumn{4}{|l|}{ Hipófisis } \\
\hline Adenohipófisis & +++ & nd & nd \\
\hline Neurohipófisis & + & & \\
\hline \multicolumn{4}{|l|}{ Adrenal } \\
\hline Cápsula & +++ & nd & nd \\
\hline Corteza: zona glomerular & + & & \\
\hline zona intermedia & +++ & & \\
\hline zona fascicular & ++ & & \\
\hline zona reticular & + & & \\
\hline Médula: endotelio de capilares & + & & \\
\hline
\end{tabular}

nd: no disponible. m: multifocal. a: células aisladas. - : sin tinción. +: tinción débil. ++: tinción moderada. +++: tinción intensa (la evaluación de la intensidad de tinción se realizó en forma subjetiva utilizando al tejido control como patrón).

abortos espontáneos $(7,5 \%)$ y no detectamos neonatos positivos. En Argentina, el vDVB ocupa el último lugar como causal de abortos de origen infeccioso, con tasas de aislamiento viral que varían de 2,6 a $4,8 \%$, siendo los agentes bacterianos la principal causa de abortos ${ }^{4,6,7}$ o enfermedad neonatal ${ }^{17}$. A pesar de estos resultados, no debe subestimarse la importancia del vDVB en la sanidad reproductiva de los bovinos de nuestra

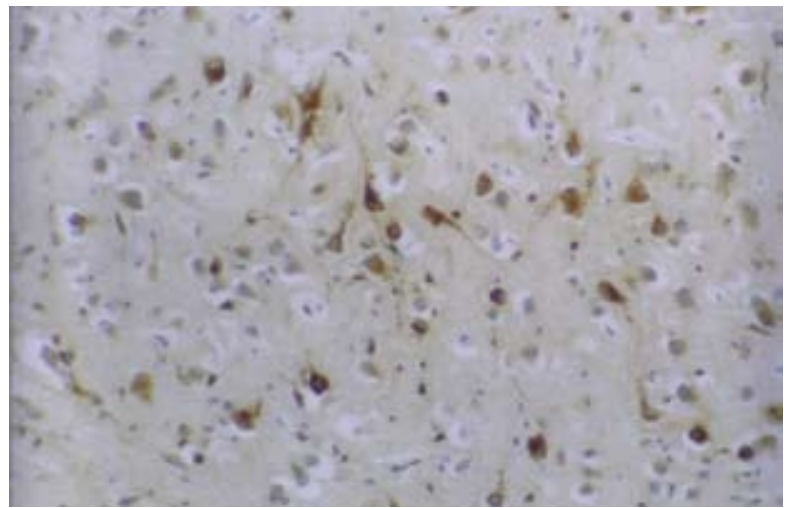

Figura 2: Corteza cerebral, feto bovino $n^{\circ} 1$. Fuerte inmunotinción en el citoplasma de las grandes neuronas del estrato piramidal. Anticuerpo monoclonal 15.c.5, dilución 1:6000 (20x). región, ya que el aborto es la consecuencia más visible de los diversos trastornos reproductivos que ocasiona este virus.

En conclusión, el estudio reveló que el vDVB está presente en los bovinos de la región y es responsable de originar abortos. El análisis inmunohistoquímico de diferentes tejidos fetales fijados en formalina permitió el diagnóstico del cuadro abortivo del vDVB. Neuro-

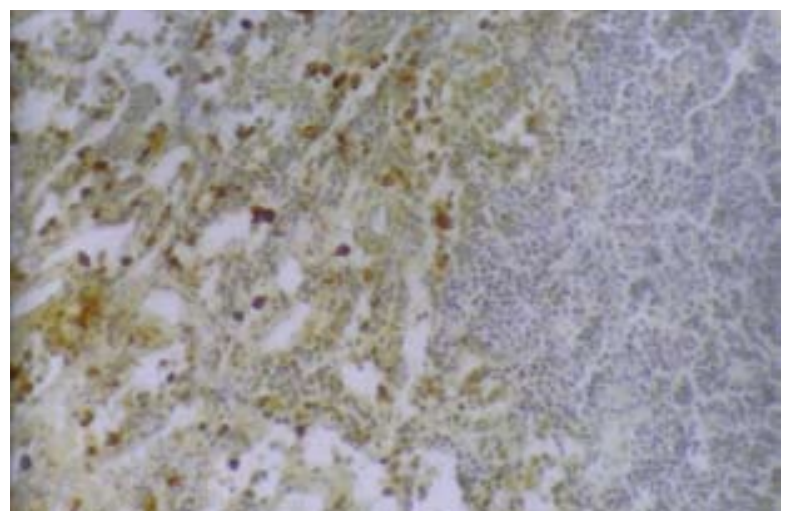

Figura 3: Nódulo linfático, feto bovino $n^{\circ} 3$. Intensa inmunotinción en macrófagos de senos y cordones medulares. Linfocitos corticales sin inmunotinción. Anticuerpos monoclonal 15.c.5, dilución 1:6000 (20x). 
nas, células epiteliales y macrófagos fueron los tipos celulares con mayor concentración de antígeno viral. Por lo tanto, se resalta la conveniencia del análisis de encéfalo, piel y nódulos linfáticos para el diagnóstico inmunohistoquímico de fetos abortados por el vDVB.

Resulta importante continuar con el diagnóstico del vDVB en tejidos fetales a fin de determinar la prevalencia de abortos atribuidos a dicha enfermedad en nuestra región. Además, queda por evaluar la técnica inmunohistoquímica empleando el anticuerpo monoclonal 15.c.5, a fin de determinar si es eficiente para detectar todas las cepas regionales del vDVB.

Agradecimientos: Al Dr. Germán Reinhardt del Instituto de Microbiología de la Facultad de Ciencias, Universidad Austral de Chile, por su contribución a este trabajo. A la Secretaría General de Ciencia y Técnica de la Universidad Nacional del Nordeste, por su aporte económico.

\section{REFERENCIAS}

1. Baszler TV, Evermann JF, Kaylor PS, Byington TC, Dilbeck PM. 1995. Diagnosis of naturally occurring bovine viral diarrhea virus infections in ruminants using monoclonal antibody-based immunohistochemistry. Vet Pathol 32: 609-618.

2. Bielefeldt Omann, H. 1995 The pathologies of bovine viral diarrhea virus infection. Vet Clin N Am Food Anim Pract 11: 447-476.

3. Campero CM, Daguerre JS, Lager I, Odriozola E. 1991. Pérdidas reproductivas y abortos ocasionados por el virus de la diarrea viral bovina en un rodeo de cría de la provincia de Buenos Aires, Argentina. Rev Med Vet 72: 62-67.

4. Campero CM, Cipolla AL, Odeón AC, Odriozola E, Moorel DP, Ronchi J. 2000. Causales de aborto y mortalidad neonatal en bovinos de la provincia de Buenos Aires, Argentina. Memorias del XXI Congreso Mundial de Buiatría, Punta del Este, Uruguay, p. 41.

5. Caropi WV, Donis RO, Dubovi EJ. 1990. Characterization of a panel of monoclonal antibodies and their use in the study of the antigenic diversity of bovine viral diarrhea virus. Am J Vet Res 51: 1388-1394.

6. Di Paola LA, Ancinas MD, Travería GE, Alvarado Pinedo MF, Sanabria R, Tassara F, Peralta LM, Romero J, Romero JR. 2008. Análisis retrospectivo de casuística de abortos bovinos (período 2002-2006). Memorias de la VI Reunión Argentina de Patología Veterinaria, Corrientes, Argentina, p. 108.

7. Draghi MG, Soni CA, Beckwith B, Zurbriggen MA, Homse AC, Rochinotti D, Alcaraz EL, Rizzi C, Caspe SG, Ramírez JC, Pereyra M, Biotti GM. 2006. Principales causas de mortalidad perinatal en bovinos en el Nordeste Argentino. Rev Med Vet 87: 140-143.

8. Dubovi EJ. 1994. Impact of bovine viral diarrhea virus on reproductive performance in cattle. Vet Clin $N$ Am Food Anim Pract 10: 503-514.

9. Ellis JA, Martin K, Norman GR, Haines DM. 1995. Comparison of detection methods for bovine viral diarr- hea virus in bovine abortions and neonatal death. $J$ Vet Diagn Invest 7: 433-436.

10. Fredriksen B, Press CM, Sandvik T, Odegaard SA, Loken T. 1999. Detection of viral antigen in placenta and fetus of cattle acutely infected with bovine viral diarrhea virus. Vet Pathol 36: 267-275.

11. Haines DM, Clark EG, Dubovi EJ. 1992. Monoclonal antibody-based immunohistochemical detection of bovine viral diarrhea virus in formalin-fixed, paraffin-embedded tissues. Vet Pathol 29: 27-32.

12. Hewicker-Trautwein M, Trautwein G, Frey HR, Liess B. 1997. Immunohistochemical studies on organ tropism of different biotypes of BVD virus in experimentally infected sheep fetuses. Dtsch Tierärztl Wszhr 104: 436-439.

13. Lertora WJ, Arzeno M, Crudeli GA. 2006. Detección de infección activa por el virus diarrea viral bovina en rebaños bovinos y bubalinos: informe preliminar. Memorias de la XXVII Sesión de Comunicaciones Cientificas de la Facultad de Ciencias Veterinarias, UNNE, Corrientes, Argentina, p. 2.

14. Lertora WJ, Sánchez Negrette M, Montenegro MA, Frías ML. 2007. Consideraciones técnicas sobre un método inmunohistoquímico para la detección del virus diarrea viral bovina en tejido fijado en formalina. Rev Vet 18 : $58-61$.

15. Kobrak A, Wever EL. 1997. Bovine diarrhea virus: an update. Rev Argent Microbiol 29: 47-61.

16. Moennig V, Liess B. 1995. Pathogenesis of intrauterine infections with bovine viral diarrhea virus. Vet Clin $\mathrm{N} \mathrm{Am}$ Food Anim Pract 11: 477-487.

17. Morrell E, Moore DP, Odeón AC, Posso MA, Odriozola E, Cantón G, Paolocchi F, Malena R, Leunda MR, Morsella C, Cano D, Campero CM. 2006. Estudio retrospectivo de mortalidad neonatal en bovinos para carne y leche. Memorias de la Quinta Reunión Argentina de Patología Veterinaria, Esperanza, Santa Fe, Argentina, p. 73.

18. Odeón AC, Späth EJ, Paloma EJ, Leunda MR, Fernández Sainz IJ, Perez SE, Kaiser GC, Draghi MG, Cetra BM, Cano A. 2001. Seroprevalencia de la diarrea viral bovina, herpesvirus bovino y virus sincicial respiratorio en Argentina. Rev Med Vet 82: 216-220.

19. Ridpath JF. 1996. Sequence diversity and genotyping. Proc. Intern. Symposium Bovine Viral Diarrhea Virus a 50 Year Review, Cornell University, USA, p. 39-42.

20. Scherer CF, Flores EF, Weiblen R, Caron L, Irigoyen LF, Neves JP, Maciel MN. 2001. Experimental infection of pregnant ewes with bovine viral diarrhea virus type-2 (BVDV-2) effects on the pregnancy and fetus. Vet Microbiol 79: 285-299.

21. Ssentongo YK, Johnson RH, Smith JR. 1980. Association of bovine viral diarrhea-mucosal disease virus with ovaritis in cattle. Aust Vet J 56: 272-274.

22. Thür B, Hilber M, Strasser M, Ehrensperger F. 1997. Immunohistochemical diagnosis of pestivirus infections associated with bovine and ovine abortion and perinatal death. Am J Vet Res 58: 1371-1375. 